\title{
Efficacy and Limitations of F-18-fluoro-2-deoxy-D-glucose Positron Emission Tomography to Differentiate Between Malignant and Benign Bone and Soft Tissue Tumors
}

\author{
SHINJI MIWA ${ }^{1}$, TAKAFUMI MOCHIZUKI ${ }^{2}$, NORIO YAMAMOTO ${ }^{1}$, TOSHIHARU SHIRAI $^{1}$, KATSUHIRO $^{2}$ \\ HAYASHI $^{1}$, AKIHIKO TAKEUCHI ${ }^{1}$, HIROYUKI INATANI ${ }^{1}$, KENTARO IGARASHI ${ }^{1}$, TAKASHI HIGUCHI ${ }^{1}$, \\ KENSAKU ABE $^{1}$, YUTA TANIGUCHI ${ }^{1}$, HISAKI AIBA ${ }^{1}$, HIROKO IKEDA $^{3}$ and HIROYUKI TSUCHIYA ${ }^{1}$ \\ ${ }^{1}$ Department of Orthopaedic Surgery, Kanazawa University Graduate School of Medical Sciences, Kanazawa, Japan; \\ ${ }^{2}$ Kanazawa Advanced Medical Center, Kanazawa, Japan; \\ ${ }^{3}$ Department of Molecular and Cellular Pathology, Kanazawa University School of Medicine, Kanazawa, Japan
}

\begin{abstract}
Background/Aim: Positron emission tomography (PET) using ${ }^{18}$ fluorine-labelled fluorodeoxyglucose (FDG), is the most widely applied molecular imaging technique in oncology. The present study assessed the efficacy and limitations of FDG-PET by comparing FDG accumulation in bone and soft tissue lesions, as well as histopathological features. Patients and Methods: The study included 122 patients with 165 lesions, as assessed by histopathological examinations. The maximum standardized uptake values $\left(S U V_{\text {max }}\right)$ of benign lesions were compared to those of primary, recurrent, or metastatic sarcomas, as well as those of other malignancies. Results: The sensitivity, specificity, and accuracy of $S U V_{\max }$ for differentiation between benign lesions and primary sarcomas were $67.9 \%, 92.9 \%$, and $80.4 \%$, respectively. There were no significant differences between benign lesions and recurrent or metastatic sarcomas. Conclusion: Although FDG-PET is a useful imaging modality to differentiate primary sarcomas from benign lesions, it is difficult to differentiate residual or metastatic sarcomas from benign lesions.
\end{abstract}

Diagnostic imaging techniques including radiography, computed tomography (CT), magnetic resonance imaging (MRI), ${ }^{201}$ thallium scintigraphy, ${ }^{99 \mathrm{~m}} \mathrm{Tc}-\mathrm{MIBI}$ scintigraphy, and positron emission tomography (PET) are widely used to assess bone and soft tissue lesions (1-5). Anatomic imaging techniques such as radiography, CT, and MRI are useful for

Correspondence to: Shinji Miwa, Department of Orthopaedic Surgery, Kanazawa University School of Medicine, 13-1 Takaramachi, Kanazawa, Ishikawa 920-8640, Japan. Tel: +81-76-2652374, e-mail: smiwa001@yahoo.co.jp

Key Words: Bone and soft tissue lesions, FDG-PET, differentiation, malignant, benign. identifying the location, extent, and association between musculoskeletal tumors and normal tissues. Although histopathological examination is the gold standard for diagnosis, biopsy and excision of the lesion are invasive, especially for patients with benign tumors. Several studies have assessed the efficacy of radiological examinations to detect malignant lesions (6-10), however, false-positive and false-negative lesions occur when differentiating bone and soft tissue lesions using radiological examinations. ${ }^{201}$ Thallium scintigraphy is also used to differentiate benign and malignant bone and soft tissue lesions (11). However, giant cell tumor (GCT), Langerhans cell histiocytosis (LCH), pigmented villonodular synovitis, and osteomyelitis have high accumulation profiles using ${ }^{201}$ Thallium scintigraphy, which often results in misdiagnoses of malignant tumor (1218). In contrast, chondrosarcoma, well-differentiated liposarcoma, chordoma, and malignant peripheral nerve sheath tumor have low accumulation profiles of the tracers.

PET with ${ }^{18}$ fluorine-labelled fluorodeoxyglucose $\left({ }^{18} \mathrm{~F}\right.$ FDG), which is the molecular imaging technique most widely applied in oncology, provides quantitative, qualitative, and functional information regarding tumor cells, based on their increased rate of glucose metabolism. FDGPET effectively and sensitively detects, stages, and restages malignancies in patients with diverse types of cancer (1924). Furthermore, the combination of PET and whole-body CT provides functional and anatomical information, resulting in accurate detection and staging of malignancies.

Several studies have reported on the efficacy of PET/CT for detection of malignant tumors and differentiation between malignant and benign lesions (25-29). Although ${ }^{18} \mathrm{~F}-\mathrm{FDG}$ accumulates preferentially in malignant tumors, it is a nonspecific tracer and accumulation also occurs in other physiological and non-malignant processes, including infective and inflammatory conditions such as osteomyelitis and 
arthritis (30). The aim of the present retrospective study was to determine whether integrated PET/CT reliably differentiates between malignant lesions and benign lesions, by comparing ${ }^{18} \mathrm{~F}-\mathrm{FDG}$ accumulation in bone and soft tissue lesions.

\section{Patients and Methods}

Patients. The present study included 122 patients (63 men, 59 women patients; mean age: 57.0 years; age range $=13-88$ years) with 165 bone and soft tissue lesions, which were assessed by PET/CT and histopathological examinations from July 2010 to November 2015. The 165 lesions included 137 malignant lesions and 28 benign lesions. The 137 malignant lesions comprised 28 primary tumors, 34 recurrent or residual tumors, 43 metastatic tumors, and 32 other malignancies including carcinomas and lymphomas. The study was approved by the Kanazawa University Ethical Committee. All participants provided written informed consent.

Integrated PET/CT acquisition. Integrated PET/CT was performed after fasting for at least $6 \mathrm{~h}$, if the serum glucose level was $\leq 200 \mathrm{mg} / \mathrm{dl}$. Each patient was injected with $4.0 \mathrm{MBq} / \mathrm{kg}(0.11 \mathrm{mCi} / \mathrm{kg})$ of $18 \mathrm{~F}-\mathrm{FDG}$, and whole-body PET/CT was performed using a PET-CT system (Discovery PET/CT 690; GE Healthcare, Milwaukee, WI, USA) 60 and $120 \mathrm{~min}$ after injection. PET/CT was performed only at the $60 \mathrm{~min}$ timepoint in cases without significant accumulation of ${ }^{18} \mathrm{~F}-\mathrm{FDG}$.

Image analysis. PET and CT images were reviewed by a physician with experience in nuclear medicine. The maximum standardized uptake value $\left(\mathrm{SUV}_{\max }\right)$ was determined in each region of interest (ROI). SUV $\mathrm{Sax}_{\max }$ was calculated using the PET scanner software, using the following formula: $\mathrm{SUV}_{\max }=C(\mu \mathrm{Ci} / \mathrm{mL}) / I D(\mu \mathrm{Ci}) / w(\mathrm{~kg})$, whereby $C$ is the activity at a pixel within the tissue defined by an ROI, $I D$ is the injected dose, and $w$ is the patient's body weight in $\mathrm{kg}$. SUV $\mathrm{max}_{\max }$ values within the selected ROI are reported.

Statistical analyses. Values are expressed as means \pm standard deviations. Comparisons of $\mathrm{SUV}_{\max }$ between 2 groups were analyzed using Student's $t$-tests. Comparisons of $\geq 2$ groups were assessed using analysis of variance. Sensitivity, specificity, positive predictive values (PPV), negative predictive values (NPV), and accuracy were calculated; and 95\% confidence intervals (CIs) were determined for each parameter, based on the binomial distribution. $\mathrm{SUV}_{\max }$ for malignant lesions were compared with that of benign lesions. Furthermore, $\mathrm{SUV}_{\max }$ of primary, recurrent, or metastatic sarcomas, as well as carcinomas, were compared with those for benign lesions. The optimal cutoff levels for $\mathrm{SUV}_{\max }$ were defined as the index values that minimized the number of false results by receiver operator characteristic analyses. Correlations between $\mathrm{SUV}_{\max }$ and histological evaluation were analyzed using measure of sensitivity, specificity, accuracy, PPV, and NPV. Statistical significance was defined as $p<0.05$. All statistical analyses were performed using EZR statistical software (Saitama Medical Center, Jichi Medical University, Saitama, Japan).

\section{Results}

Comparisons of $S U V_{\max }$ between benign and malignant lesions. The mean $\mathrm{SUV}_{\max }$ for benign lesions and malignant tumors were $4.9 \pm 3.4$ and 8.8 46.7 , respectively (Figure 1).
Although there was a significant difference between values for benign and malignant lesions $(p=0.001)$, considerable overlap was observed. For malignant tumors, the mean SUV $_{\max }$ of primary sarcomas, recurrent sarcomas, metastatic sarcomas, and the other malignancies were 13.1 \pm 7.6 , 6.2 $\pm 5.7,6.6 \pm 5.1$, and 10.8 \pm 6.7 , respectively (Figure 2). Primary sarcomas and other malignancies had significantly higher $\mathrm{SUV}_{\max }$ compared to benign lesions (Figure 2; $p<0.01$ ), whereas no significant differences occured between benign lesions and recurrent or metastatic lesions (Figure 2).

Sensitivity, specificity, and accuracy of FDG-PET. The sensitivity, specificity, PPV, NPV, and accuracy of SUV $\mathrm{max}_{\max }$ for differentiating between benign lesions and malignant tumors were $92.9 \%, 43.8 \%, 96.8 \%, 25.2 \%$, and $52.1 \%$, respectively, with an optimal cutoff $\mathrm{SUV}_{\max }$ value of 8.2 (Figure 3A; Table I). The sensitivity, specificity, PPV, NPV, and accuracy of $\mathrm{SUV}_{\max }$ for differentiating benign lesions from primary sarcomas were $67.9 \%, 92.9 \%, 90.5 \%, 74.3 \%$, and $80.4 \%$, respectively, with an optimal cutoff $\mathrm{SUV}_{\max }$ of 8.6 (Figure 3B; Table I).

False positives and false negatives using PET/CT. Although $\mathrm{SUV}_{\max }$ for malignant lesions ROIs were significantly higher compared to those for benign lesion ROIs, considerable overlaps in $\mathrm{SUV}_{\max }$ were observed (Table II). There were 2 false positives among the benign lesion cases, including 1 each of GCT and LCH. There were 9 false negative cases among the primary sarcomas, including the following types of sarcomas: 2 extraskeletal myxoid chondrosarcomas, 2 Ewing's sarcomas, 1 chondrosarcoma, 1 leiomyosarcoma, 1 osteosarcoma, 1 epithelioid endothelioma, and 1 undifferentiated pleomorphic sarcoma (UPS). In the present study, 1 case of LCH and 4 cases of GCT were categorized as benign lesions. Therefore, the mean $\mathrm{SUV}_{\text {max }}$ for LCH was 14.8 and the mean $\mathrm{SUV}_{\text {max }}$ for GCT was 8.4 (range=3.6-13.8) (Figure 4), which was higher than for the other types of benign lesions. Cases of multiple lesions including malignancies also made it difficult to differentiate between benign lesions and metastatic lesions. For example, $\mathrm{PET} / \mathrm{CT}$ in a 68-year-old patient indicated multiple lesions (Figure 5), and histological examinations of the thyroid, left buttock, and ilium revealed thyroid cancer, undifferentiated pleomorphic sarcoma, and sclerotic bone without tumor, respectively.

\section{Discussion}

PET $\mathrm{SUV}_{\max }$ has been proposed as diagnostic tools to differentiate between benign and malignant lesions $(31,32)$. Cho et al. (31). reported that PET/CT is an adjunctive diagnostic method for differentiating malignant lesions from vertebral compression fractures. Additionally, Tian et al. reported that malignant lesions have higher $\mathrm{SUV}_{\max }$ than 


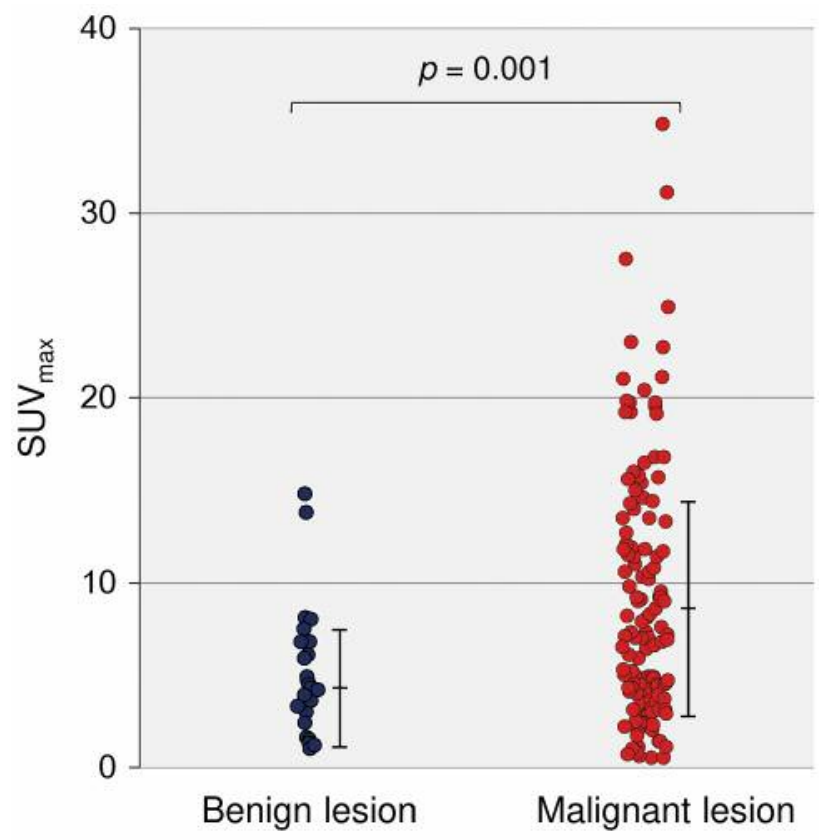

Figure 1. Maximum standardized uptake values $\left(S U V_{\max }\right)$ in benign and malignant lesions. Malignant lesions included primary sarcomas, recurrent sarcomas, metastatic sarcomas, and other malignancies. The data are expressed means \pm standard deviation (SDs). Statistical analyses were performed using Student's t-tests.

Table I. Efficacy of $S U V_{\max }$ for differentiating between benign and malignant lesions.

\begin{tabular}{lccllc}
\hline & \multicolumn{2}{c}{$\begin{array}{c}\text { Benign and malignant } \\
\text { lesions* }\end{array}$} & & \multicolumn{2}{c}{$\begin{array}{c}\text { Benign lesions and } \\
\text { primary sarcomas }\end{array}$} \\
\cline { 2 - 3 } \cline { 6 - 6 } \cline { 5 - 6 } & Value & $95 \% \mathrm{CI}$ & & Value & $95 \% \mathrm{CI}$ \\
\hline Sensitivity & $43.8 \%$ & $40.9-44.8 \%$ & & $67.9 \%$ & $56.5-72.9 \%$ \\
Specificity & $92.9 \%$ & $78.7-98.0 \%$ & & $92.9 \%$ & $81.5-97.9 \%$ \\
PPV & $96.8 \%$ & $90.4-99.1 \%$ & & $90.5 \%$ & $75.4-97.2 \%$ \\
NPV & $25.2 \%$ & $21.4-26.6 \%$ & & $74.3 \%$ & $65.2-78.3 \%$ \\
Accuracy & $52.1 \%$ & $47.3-53.9 \%$ & & $80.4 \%$ & $69.0-85.4 \%$ \\
\hline
\end{tabular}

* Malignant lesions included primary sarcomas, recurrent sarcomas, metastatic sarcomas, and carcinomas. $\mathrm{SUV}_{\max }$ : Maximum standardized uptake value; PPV: positive predictive value; NPV: negative predictive value; CI: confidence interval.

benign lesions (malignant lesions, 6.8; benign lesions, 4.5), although considerable overlap was observed (32). Our data also demonstrate significant differences in $\mathrm{SUV}_{\max }$ between benign and malignant lesions, although we also observed considerable overlap in $\mathrm{SUV}_{\max }$ between groups. Among malignant lesions, the mean $\mathrm{SUV}_{\max }$ for primary tumors,

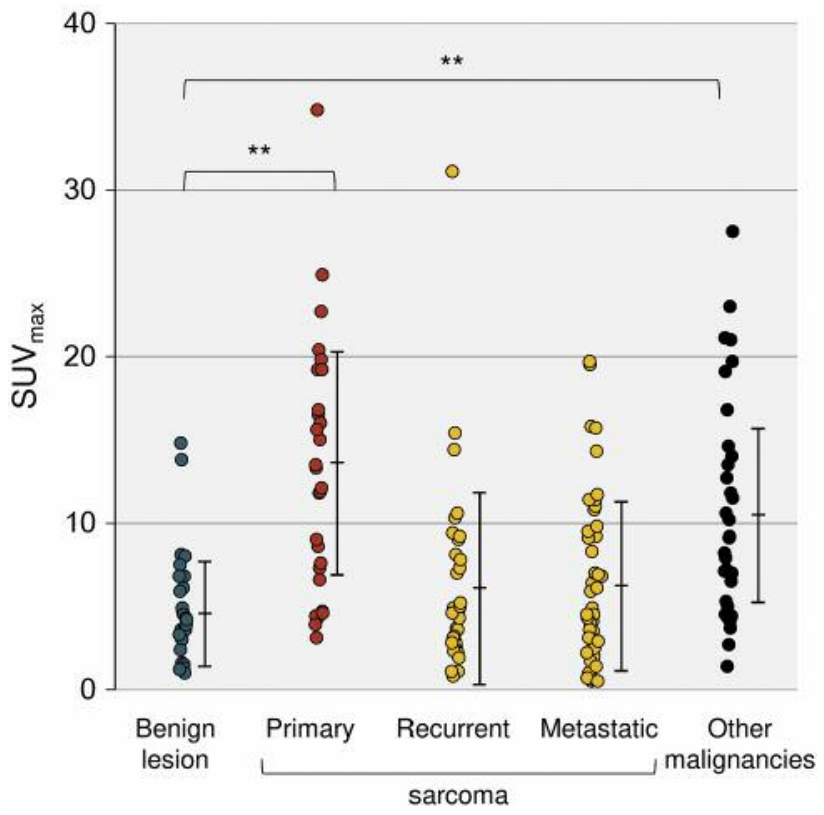

Figure 2. Maximum standardized uptake values $\left(S U V_{\max }\right)$ in benign lesions, primary sarcomas, recurrent sarcomas, metastatic sarcomas, and other malignancies. The data are expressed means \pm standard deviation (SDs). Statistical analyses were performed using analysis of variance (ANOVA). **p<0.01.

Table II. False-positive and false-negative cases assessed by positron emission tomography/computed tomography.

\begin{tabular}{lcr}
\hline & Pathological diagnoses & $\mathrm{SUV}_{\max }$ \\
\hline False positive cases & Langerhans cell histiocytosis & 14.8 \\
& Giant cell tumor & 13.8 \\
False negative cases & Chondrosarcoma (grade 2) & 3.1 \\
& Extraskeletal myxoid chondrosarcoma & 3.9 \\
& Epithelioid endothelioma & 4.3 \\
& Osteosarcoma & 4.4 \\
& Extraskeletal myxoid chondrosarcoma & 4.6 \\
& Undifferentiated pleomorphic sarcoma & 4.7 \\
& Ewing's sarcoma & 6.6 \\
& Ewing's sarcoma & 7.3 \\
Leiomyosarcoma & 7.6 \\
\hline
\end{tabular}

recurrent tumors, and metastatic tumors were 13.1 \pm 7.6 , $6.2 \pm 5.7,6.6 \pm 5.1$, and $10.8 \pm 6.7$, respectively. Most primary sarcomas in our study were large masses at the time of diagnosis. In contrast, the recurrent and metastatic tumors in our study were small masses, primarily because most patients had follow-up examinations such as CT and MRI to 

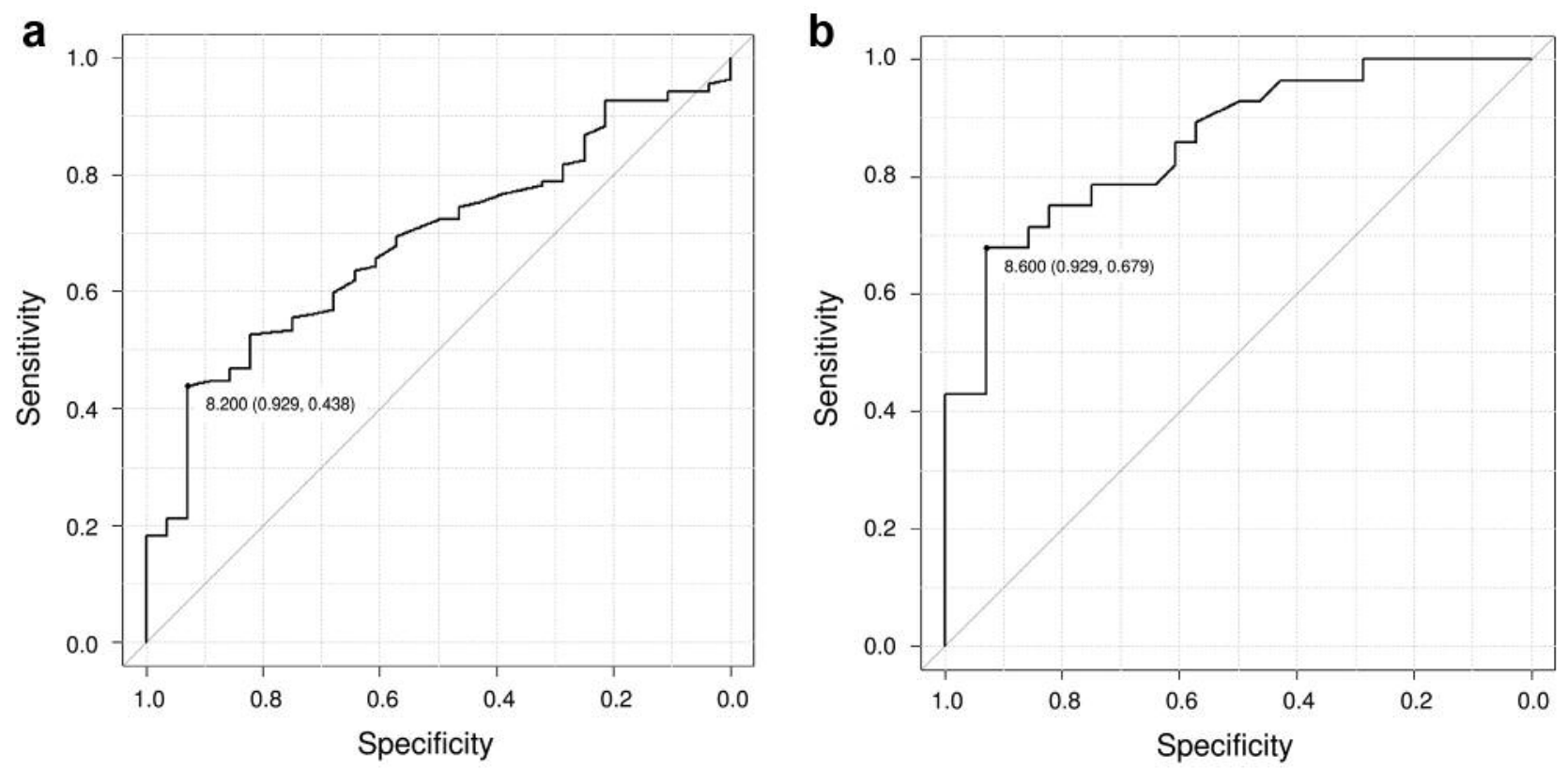

Figure 3. Receiver operator characteristic (ROC) analysis to differentiate between benign and malignant lesions. A: Benign lesions and malignant lesions. Malignant lesions included primary sarcomas, recurrent sarcomas, metastatic sarcomas, and other malignancies. B: Benign lesions and primary sarcomas.

detect lesions. Therefore, the differences in $\mathrm{SUV}_{\max }$ between primary, recurrent, and metastatic sarcomas may be related to tumor size.

Discrepancies between $\mathrm{SUV}_{\max }$ and malignancy determination have been reported for some tumors (33-35). In our study, LCHs had the highest $\mathrm{SUV}_{\max }$ among benign lesions, and the mean $\mathrm{SUV}_{\max }$ for GCTs was higher (8.4, range $=3.6-13.8)$ than for other benign lesions. Cellular uptake of FDG in human tumor cells is associated with expression of glucose transporter protein (GLUT)-1, hexokinase II, and with gene upregulation for these proteins $(34,36)$. Ong et al. found significantly greater GLUT-1 and hexokinase II in 5 different human cancer cell lines (37). However, other studies have demonstrated an up-regulation of GLUT-1 in human monocyte-derived macrophages (38-40), and the high monocyte/macrophage content within GCTs may explain the FDG uptake $(34,35)$. Therefore, GCT and lesions containing active macrophages should be considered in differential diagnoses of intensely FDG-avid neoplasms. In contrast, SUV $_{\text {max }}$ values for liposarcoma and chondrosarcoma are usually lower in PET studies, compared to values for other types of malignancies (41). However, SUV $\mathrm{max}_{\max }$ cut-offs may enable prediction of malignancies in lipomatous and cartilaginous tumors. In a previous report assessing $\mathrm{SUV}_{\max }$ in lipomatous tumors, a cut-off value of 0.81 for FDG-PET significantly differentiated between benign lesions and welldifferentiated liposarcoma (41). Feldman et al. reported that the sensitivity, specificity, and accuracy of FDG-PET for distinguishing benign and malignant cartilage neoplasms with a cutoff $\mathrm{SUV}_{\max }$ values of 2.0 were $91 \%, 100 \%$, and $97 \%$, respectively (42). Therefore, cases of suspected lipomatous or cartilaginous tumors indicated by MRI or CT should use a low SUV $_{\max }$ cut-off to differentiate between benign and malignant tumors.

Although our data demonstrate significant differences between benign and malignant lesions, considerable overlaps in $\mathrm{SUV}_{\max }$ were observed. Furthermore, the inclusion criteria for the present study were limited. The first inclusion limitation was that PET/CT was performed only for lesions that were suspected as malignancies; most of the benign lesions that were suspected as malignant tumors before PET were aggressive tumors such as GCTs. The second inclusion limitation was that the present study included only lesions that were confirmed by histopathological examinations. Exclusion of conventional benign tumors from the study may have influenced $\mathrm{SUV}_{\max }$.

In conclusion, PET is a useful imaging modality for differentiation between benign lesions and primary sarcomas, with $80.4 \%$ accuracy. However, differentiation between benign lesions and recurrent or metastatic lesions is difficult because of low FDG uptake in many types of lesions. Therefore, combinations of PET and other methods such as enhanced MRI are preferable for determining diagnoses.

\section{Conflicts of Interest}

The Authors declare that they have no competing interests. 
a

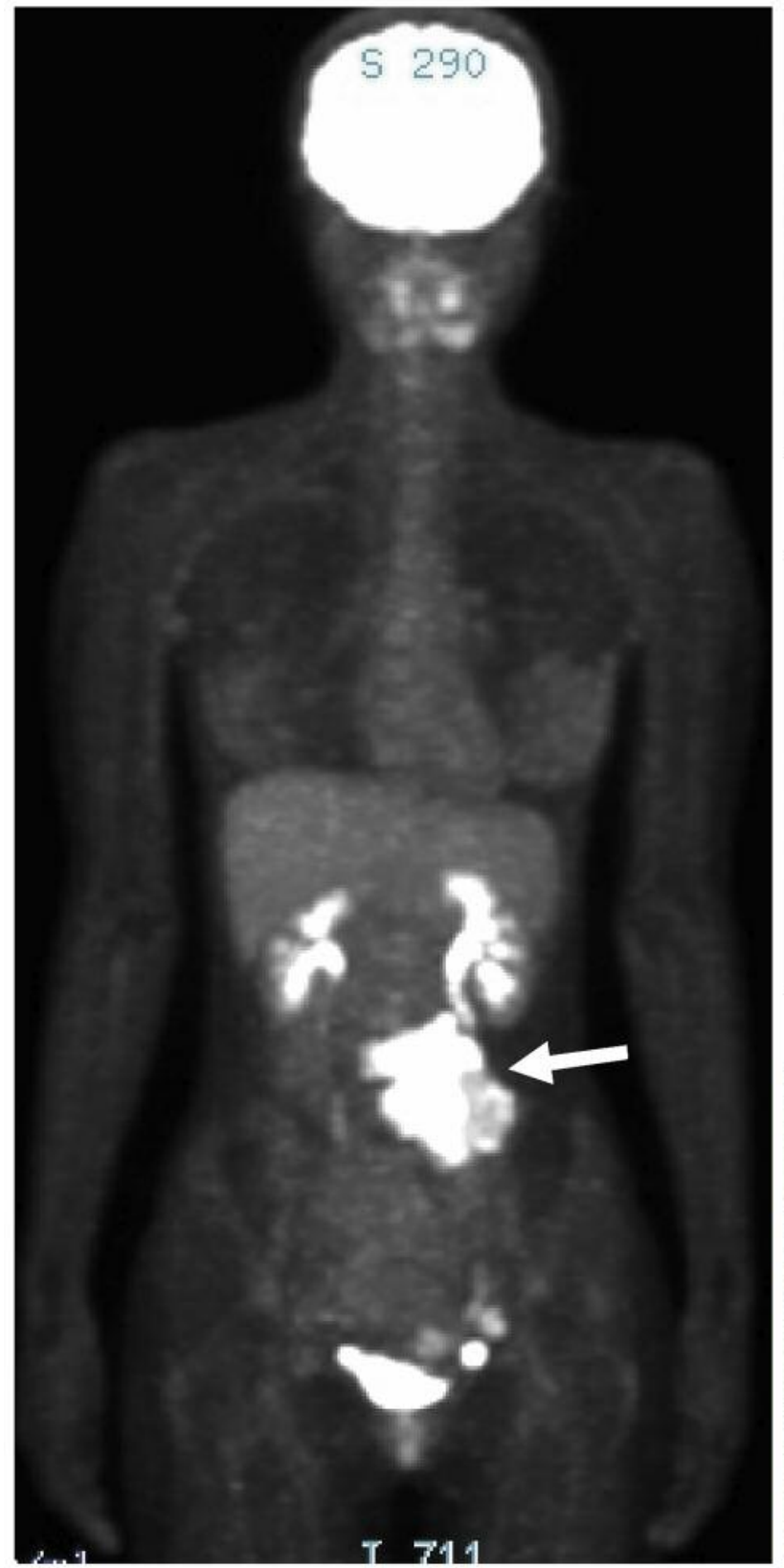

b

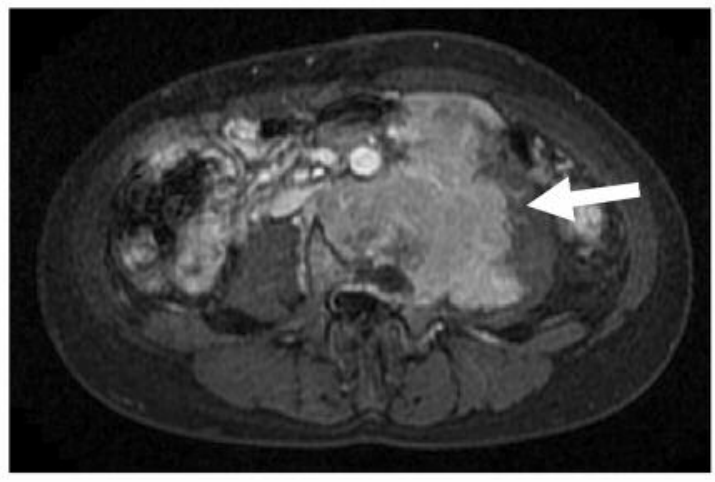

C

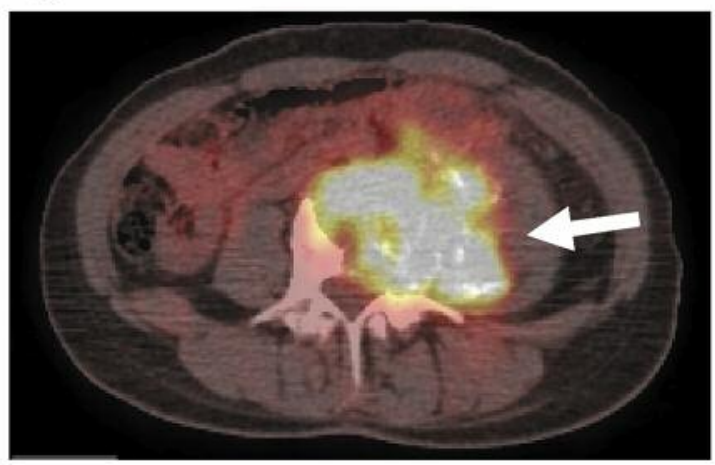

d

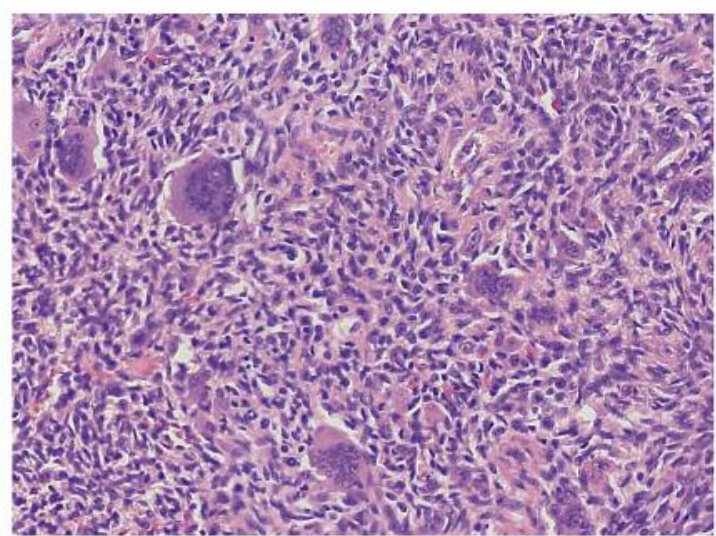

Figure 4. A 25-year-old woman with giant cell tumor (GCT) in lumbar vertebral bone. A: A whole-body positron emission tomography (PET) shows fluorodeoxyglucose (FDG) accumulation in lumbar vertebrae. B: Magnetic resonance imaging (MRI) shows a large mass on the lumbar vertebrae (white arrow). C: Fused positron emission tomography/computed tomography $(P E T / C T)$ image. Maximum standardized uptake value $\left(S U V_{\text {max }}\right)=13.8$ (white arrow). D: Hematoxylin and eosin (HE) staining.

\section{References}

1 Miwa S, Shirai T, Taki J, Sumiya H, Nishida H, Hayashi K, Takeuchi A, Ooi A and Tsuchiya H: Use of 99mTc-MIBI scintigraphy in the Evaluation of the Response to Chemotherapy for Osteosarcoma: Comparison with 201Tl scintigraphy and angiography. Int J Clin Oncol 16: 373-378, 2011.
2 Miwa S, Taki J, Yamamoto N, Shirai T, Nishida H, Hayashi K, Tanzawa Y, Kimura H, Takeuchi A, Igarashi K, Ooi A and Tsuchiya H: A novel combined radiological method for evaluation of the response to chemotherapy for primary bone sarcoma. J Surg Oncol 106: 273-239, 2012.

3 Fisher SM, Joodi R, Madhuranthakam AJ, Oz OK, Sharma R and Chhabra A: Current utilities of imaging in grading 
a
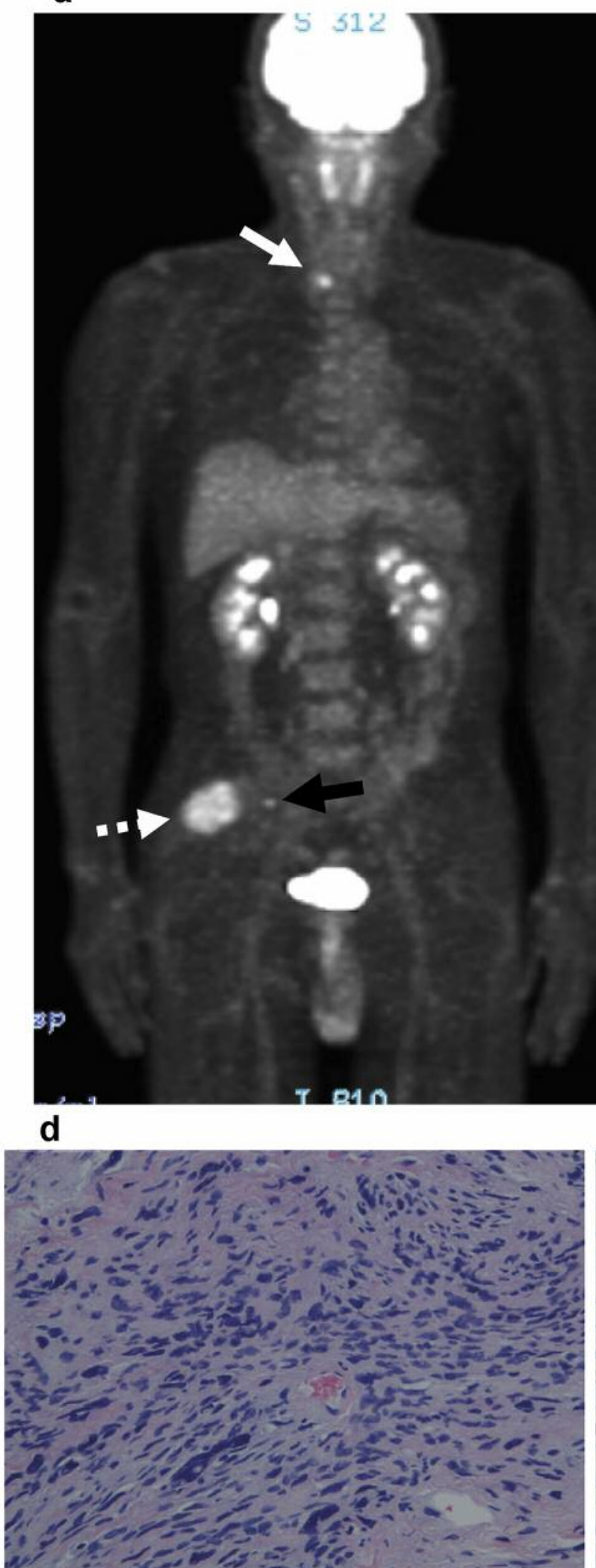

b

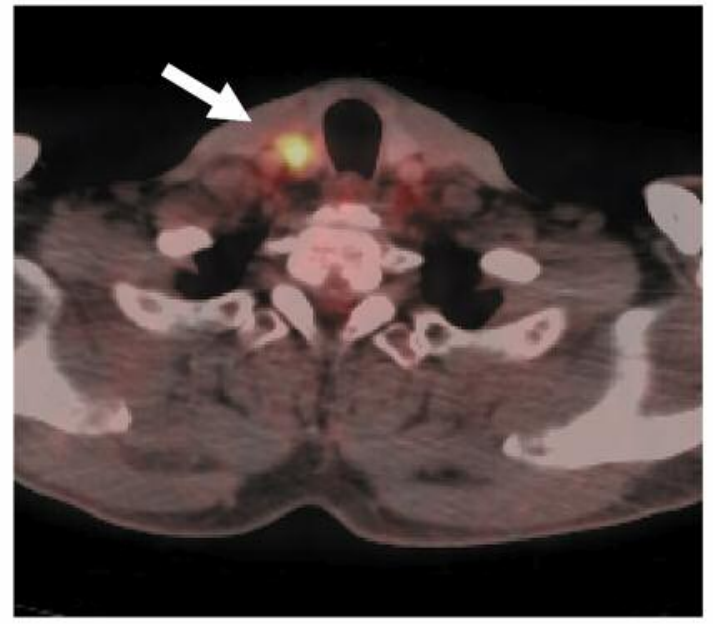

C

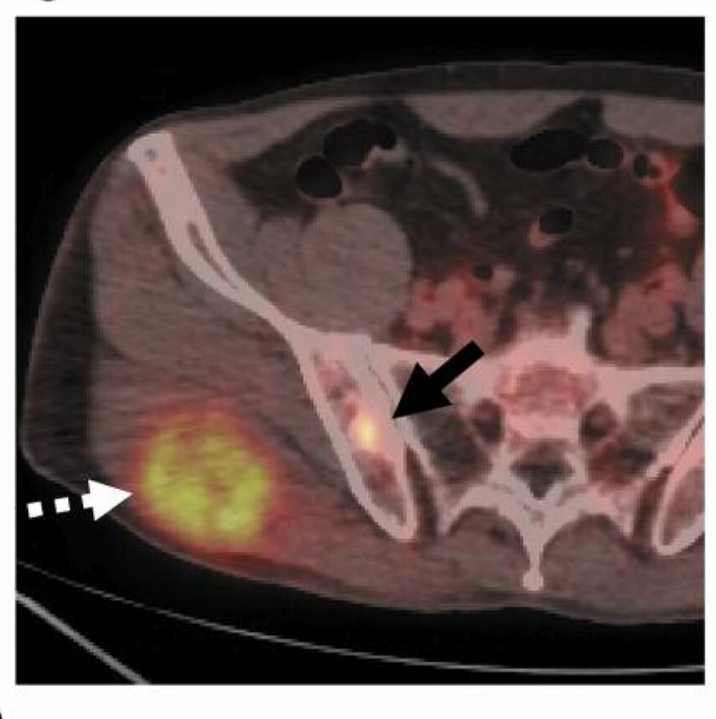

e

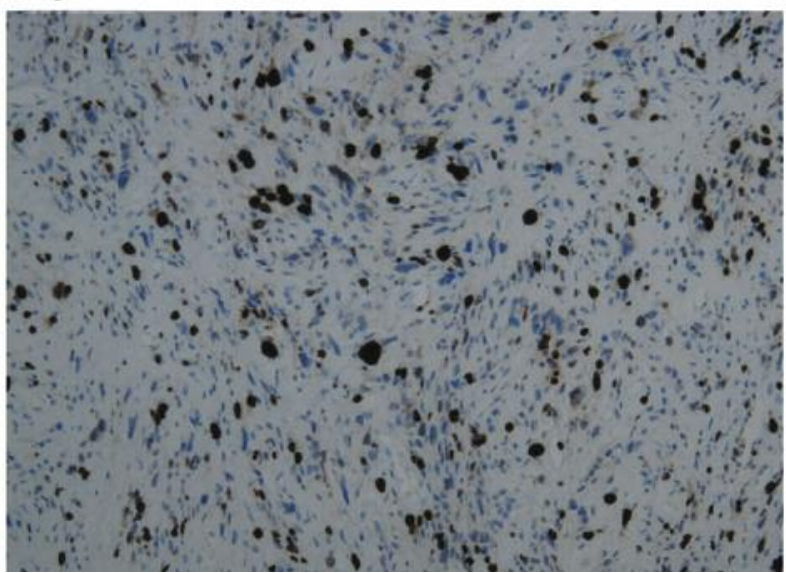

Figure 5. Continued 


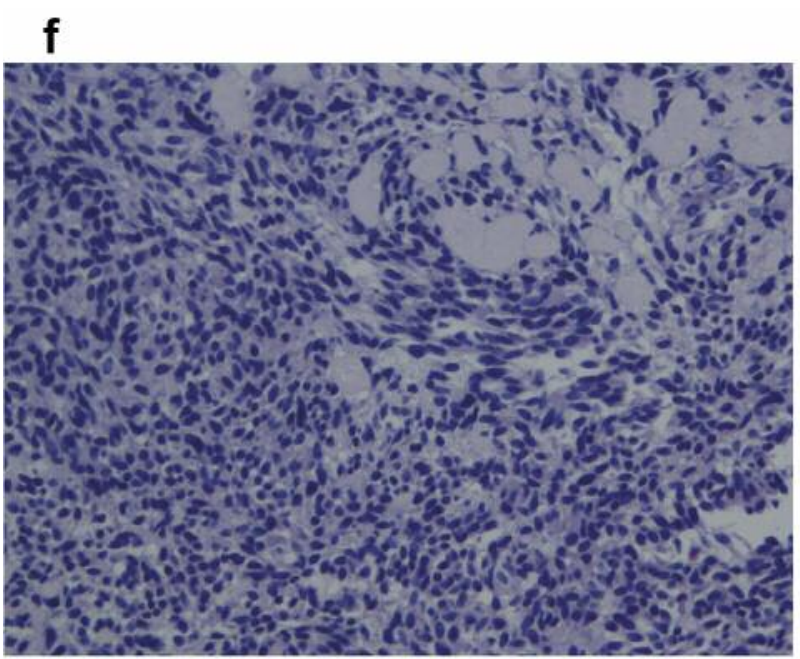

\section{g}

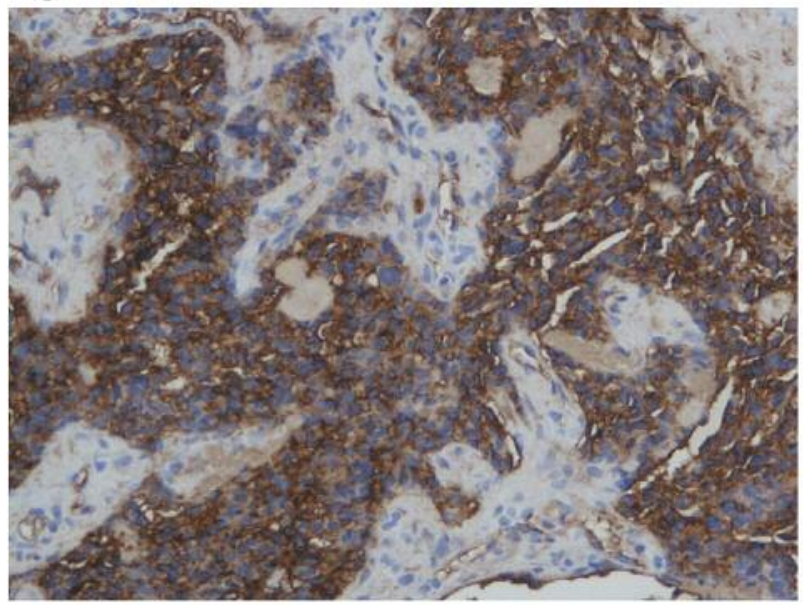

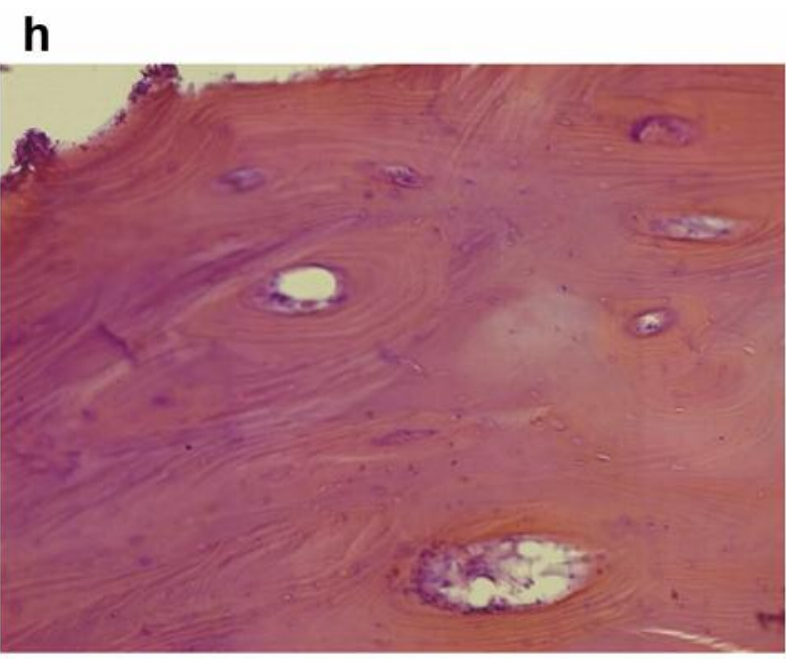

Figure 5. A 68-year-old man with undifferentiated pleomorphic sarcoma and medullary-type thyroid cancer. Positron emission tomography/ computed tomography $(P E T / C T)$ revealed multiple lesions in thyroid, left buttock, and ilium $(A, B, C)$. Histology of the left buttock and thyroid tumors showed an undifferentiated pleomorphic sarcoma $(D, E)$ and medullary-type thyroid cancer, respectively $(F, G)$. A specimen from a bone lesion in the ilium showed only sclerotic bone without tumor tissue (H). A: Whole-body image obtained with fluorodeoxyglucose-labeled (FDG-PET). B: Fused PET/CT image (thyroid). Maximum standardized uptake value $\left(S U V_{\max }\right)=5.3$ (white arrow). C: Fused PET/CT image (pelvis). $S U V_{\max }=4.9$ (dotted white arrow), $S U V_{\max }=3.3$ (black arrow). D: Hematoxylin and eosin (HE) staining of the soft tissue tumor in the left buttock. E: Ki-67 staining of soft tissue tumor in the left buttock. F: HE staining of thyroid lesion. G: Calcitonin staining of the thyroid lesion. H: HE staining of the bone lesion in the ilium. musculoskeletal soft tissue sarcomas. Eur J Radiol 85: 13361344, 2016.

4 Noebauer-Huhmann IM, Weber MA, Lalam RK, Trattnig S, Bohndorf K, Vanhoenacker F, Tagliafico A, van Rijswijk C, Vilanova JC, Afonso PD, Breitenseher M, Beggs I, Robinson P, de Jonge MC, Krestan C and Bloem JL: Soft Tissue Tumors in Adults: ESSR-Approved Guidelines for Diagnostic Imaging. Semin Musculoskelet Radiol 19: 475-482, 2015.

5 Morley $\mathrm{N}$ and Omar I: Imaging evaluation of musculoskeletal tumors. Cancer Treat Res 162: 9-29, 2014.

6 Matthies A, Ezziddin S, Ulrich EM, Palmedo H, Biersack HJ, Bender $\mathrm{H}$ and Guhlke S: Imaging of prostate cancer metastases with ${ }^{18}$ F-fluoroacetate using PET/CT. Eur J Nucl Med Mol Imaging 31: 797, 2004.

7 Cimitan M, Bortolus R, Morassut S, Canzonieri V, Garbeglio A, Baresic T, Borsatti E, Drigo A and Trovò MG: $\left[{ }^{18} \mathrm{~F}\right]$ fluorocholine PET/CT imaging for the detection of recurrent prostate cancer at PSA relapse: experience in 100 consecutive patients. Eur J Nucl Med Mol Imaging 33: 1387-1398, 2006.

8 Quon A, Chang ST, Chin F, Kamaya A, Dick DW, Loo BW Jr., Gambhir SS and Koong AC: Initial evaluation of ${ }^{18} \mathrm{~F}$ - fluorothymidine (FLT) PET/CT scanning for primarypancreatic cancer. Eur J Nucl Med Mol Imaging 35: 527-531, 2008.

9 Chowdhury FU, Bradley KM and Gleeson FV: The role of ${ }^{18} \mathrm{~F}$ FDG PET/CT in the evaluation of esophageal carcinoma. Clin Radiol 63: 1297-1309, 2008.

10 Demura $\mathrm{Y}$, Tsuchida $\mathrm{T}$, Ishizaki $\mathrm{T}$, Mizuno $\mathrm{S}$, Totani $\mathrm{Y}$, Ameshima S, Miyamori I, Sasaki M and Yonekura Y: ${ }^{18} \mathrm{~F}-\mathrm{FDG}$ accumulation with PET for differentiation between benign and malignant lesions in the thorax. J Nucl Med 44: 540-548, 2003.

11 Elgazzar AH, Malki AA, Abdel-Dayem HM, Mahmoud A, Sahweil A, Razzak S, Jahan S, el-Sayed M and Omar YT: Role of thallium-201 in the diagnosis of solitary bone lesions. Nucl Med Commun 10: 477-485, 1989.

12 Taki J, Sumiya H, Tsuchiya H, Tomita K, Nonomura A and Tonami $\mathrm{N}$ : Evaluating benign and malignant bone and soft tissue lesions with technetium-99m-MIBI scintigraphy. J Nucl Med 38: 501-506, 1997.

13 Kawakami N, Kunisada T, Sato S, Morimoto Y, Tanaka M, Sasaki T, Sugihara S, Yanai H, Kanazawa S and Ozaki T: Thallium-201 scintigraphy is an effective diagnostic modality to distinguish malignant from benign soft-tissue tumors. Clin Nucl Med 36: 982-986, 2011. 
14 Mackie GC: Pigmented villonodular synovitis and giant cell tumor of the tendon sheath: scintigraphic findings in 10 cases. Clin Nucl Med 28: 881-885, 2003.

15 Higuchi T, Taki J, Sumiya H, Kinuya S, Bunko H, Nonomura A, Tsuchiya $\mathrm{H}$ and Tonami N: Intense $201 \mathrm{Tl}$ uptake in giant-cell tumour of bone. Nucl Med Commun 23: 595-599, 2002.

16 Sato O, Kawai A, Ozaki T, Kunisada T, Danura T and Inoue H: Value of thallium-201 scintigraphy in bone and soft tissue tumors. J Orthop Sci 3: 297-303, 1998.

17 Bar-Sever Z, Connolly LP, Jaramillo D and Treves ST: Thallium-201 uptake in Langerhans cell histiocytosis of bone. Pediatr Radiol 26: 739-741, 1996.

18 Yoshikawa M, Sugawara Y, Kikuchi T, Nakata S, Mochizuki T, Ikezoe J and Sakayama K: Two cases of pediatric bone disease (eosinophilic granuloma and Brodie's abscess) showing similar scintigraphic and radiographic findings. Clin Nucl Med 25: 986990,2000

19 Aoki J, Watanabe H, Shinozaki T, Takagishi K, Ishijima H, Oya $\mathrm{N}$, Sato N, Inoue T and Endo K: FDG PET of primary benign and malignant bone tumors: standardized uptake value in 52 lesions. Radiology 219: 774-777, 2001.

20 Brenner W, Conrad EU and Eary JF: FDG PET imaging for grading and prediction of outcome in chondrosarcoma patients. Eur J Nucl Med Mol Imaging 31: 189-195, 2004.

21 Hilner BE, Siegel BA, Liu D, Shields AF, Gareen IF, Hanna L, Stine $\mathrm{SH}$ and Coleman RE: Impact of positron emission tomography/computed tomography and positron emission tomography (PET) alone on expected management of patients with cancer: initial results from the National Oncologic PET Registry. J Clin Oncol 26: 2155-2161, 2008.

22 Israel O, Mor M, Gaitini D, Keidar Z, Guralnik L, Engel A, Frenkel A, Bar-Shalom R and Kuten A: Combined functional and structural evaluation of cancer patients with a hybrid camera-based PET/CT system using (18)F-FDG. J Nucl Med 43: 1129-1136, 2002.

23 Antoch G, Saoudi N, Kuehl H, Dahmen G, Mueller SP, Beyer T, Bockisch A, Debatin JF and Freudenberg LS: Accuracy of wholebody dual-modality fluorine-18-2-fluoro-2-deoxy-D-glucose positron emission tomography and computed tomography (FDG$\mathrm{PET} / \mathrm{CT}$ ) for tumor staging in solid tumors: comparison with CT and PET. J Clin Oncol 22: 4357-4368, 2004.

24 von Schulthess GK, Steinert HC and Hany TF: Integrated PET/CT: current applications and future directions. Radiology 238: 405-422, 2006.

25 Al-Ibraheem A, Buck AK, Benz MR, Rudert M, Beer AJ, Mansour A, Pomykala KL, Haller B, Juenger H, Scheidhauer K, Schwaiger $\mathrm{M}$ and Herrmann $\mathrm{K}$ : ${ }^{18} \mathrm{~F}$-fluorodeoxyglucose positron emission tomography/computed tomography for the detection of recurrent bone and soft tissue sarcoma. Cancer 119: 1227-1234, 2013.

26 Bischoff M, Bischoff G, Buck A, von Baer A, Pauls S, Scheffold F, Schultheiss M, Gebhard F and Reske SN: Integrated FDGPET-CT: its role in the assessment of bone and soft tissue tumors. Arch Orthop Trauma Surg 130: 819-827, 2010.

27 Fuglø HM, Jørgensen SM, Loft A, Hovgaard D and Petersen MM: The diagnostic and prognostic value of ${ }^{18} \mathrm{~F}-\mathrm{FDG}$ PET/CT in the initial assessment of high-grade bone and soft tissue sarcoma. A retrospective study of 89 patients. Eur J Nucl Med Mol Imaging 39: 1416-1424, 2012.

28 Lakkaraju A, Patel CN, Bradley KM and Scarsbrook AF: PET/CT in primary musculoskeletal tumours: a step forward. Eur Radiol 20: 2959-2972, 2010.
29 Nanni C, Marzola MC, Rubello D and Fanti S: Positron emission tomography for the evaluation of soft-tissue sarcomas and bone sarcomas. Eur J Nucl Med Mol Imaging 36: 1940-1943, 2009.

30 Feldman F, van Heertum R and Manos C: ${ }^{18}$ FDG PET scanning of benign and malignant musculoskeletal lesions. Skeletal Radiol 32: 201-208, 2003.

31 Cho WI and Chang UK: Comparison of MR imaging and FDG$\mathrm{PET} / \mathrm{CT}$ in the differential diagnosis of benign and malignant vertebral compression fractures. J Neurosurg Spine 14: 177-183, 2011.

32 Tian R, Su M, Tian Y, Li F, Li L, Kuang A and Zeng J: Dual-time point PET/CT with F-18 FDG for the differentiation of malignant and benign bone lesions. Skeletal Radiol 38: 451-458, 2009.

33 Hoshi M, Takada J, Oebisu N, Hata K, Ieguchi M and Nakamura $\mathrm{H}$ : Overexpression of hexokinase- 2 in giant cell tumor of bone is associated with false positive in bone tumor on FDG-PET/CT. Arch Orthop Trauma Surg 132: 1561-1568, 2012.

34 Selby L, Kukar M, Wang J, Beg M and Sullivan J: Pigmented villous nodular synovitis mimicking metastatic melanoma on PET-CT. Int J Surg Case Rep 5: 231-233, 2014.

35 Pallas A, Hagge R, Borys D and Hunter J: Intense FDG uptake in an intra-articular localized giant-cell tumor of the tendon sheath (pigmented villonodular synovitis) mimics metastatic melanoma. Radiology Case Reports 4: 1-4, 2009.

36 Hamada K, Tomita Y, Qiu Y, Zhang B, Ueda T, Myoui A, Higuchi I, Yoshikawa H, Aozasa K and Hatazawa J: ${ }^{18}$ F-FDGPET of musculoskeletal tumors: a correlation with the expression of glucose transporter 1 and hexokinase II. Ann Nucl Med 22: 699-705, 2008.

37 Ong LC, Jin Y, Song IC, Yu S, Zhang K and Chow PK: 2-[18F]2-deoxy-D-glucose (FDG) uptake in human tumor cells is related to the expression of GLUT-1 and hexokinase II. Acta Radiol 49: 1145-1153, 2008.

38 Burke B, Giannoudis A, Corke KP, Gill D, Wells M, ZieglerHeitbrock L and Lewis CE: Hypoxia-induced gene expression in human macrophages: implications for ischemic tissues and hypoxiaregulated gene therapy. Am J Pathol 163: 1233-1243, 2003.

39 Malide D, Davies-Hill TM, Levine M and Simpson IA: Distinct localization of GLUT-1, -3 , and -5 in human monocyte-derived macrophages: effects of cell activation. Am J Physiol 274: E516526, 1998.

$40 \mathrm{Fu}$ Y, Maianu L, Melbert BR and Garvey WT: Facilitative glucose transporter gene expression in human lymphocytes, monocytes, and macrophages: a role for GLUT isoforms 1, 3, and 5 in the immune response and foam cell formation. Blood Cells Mol Dis 32: 182-190, 2004.

41 Suzuki R, Watanabe H, Yanagawa T, Sato J, Shinozaki T, Suzuki $\mathrm{H}$, Endo K and Takagishi K: PET evaluation of fatty tumors in the extremity: possibility of using the standardized uptake value (SUV) to differentiate benign tumors from liposarcoma. Ann Nucl Med 19: 661-670, 2005.

42 Feldman F, Van Heertum R, Saxena C and Parisien M: ${ }^{18}$ FDGPET applications for cartilage neoplasms. Skeletal Radiol 34: 367-374, 2005. 